\title{
LIMA FILHO, Manuel F.; ABREU, Regina e ATHIAS, Renato (orgs.). 2016. Museus e Atores Sociais: perspectivas antropológicas. Recife: Editora UFPE. 290pp.
}

\author{
RENATA MONTECHLARE
}

A Associação Brasileira de Antropologia deu sequência à série de estudos que vem publicando desde 2007 sobre museus e patrimônios convidando três especialistas no tema a organizar este volume. Regina Abreu, Renato Athias e Manuel Ferreira Lima Filho apresentam Museus e atores sociais: perspectivas antropológicas tratando de museus e coleções etnográficas como lugares "valorativos" de construção de diferenças. O livro lançado em 2016 faz parte de um conjunto de outros dois volumes proposto por seu Comitê de Patrimônio e Museus, no intuito de estimular novos pesquisadores a dedicarem-se a este programa de pesquisa. O primeiro, Antropologia e patrimônio cultural: diálogos e desafios contemporâneos, foi organizado por Manuel Ferreira Lima Filho, Cornélia Eckert e Jane Beltrão. E o segundo, Antropologia e patrimônio cultural: trajetórias e conceitos, conduzido por Izabela Tamaso e Manuel Ferreira Lima Filho, e publicado em 2012. Museus e atores sociais, como a terceira publicação nesta linha, teve origem no Seminário Internacional ocorrido como parte dos pré-eventos da 29a RBA na Universidade Federal do Rio Grande do Norte, nos dias 01 e 02 de agosto de 2014.

Conectado aos principais temas de debate no mundo dos museus de antropologia, este terceiro volume apresenta uma série de trabalhos que partem de museus e coleções ou de artefatos etnográficos que em seguida os integrarão. Neste trânsito entre seu local de origem e a instituição que os abriga, os materiais sofrem dezenas de reclassificações desde o momento em que são produzidos e destacados por seus grupos, até alcançarem a percepção de pesquisadores, colecionadores e demais interessados externos. Atribuições de valor e sentido variam no tempo, portanto cada abordagem trazida no livro atravessa perspectivas disciplinares e metodológicas características dos períodos estudados, apresentando ao leitor oscilações classificatórias que, por sua vez, articulam-se às teorias antropológicas e às práticas de colecionamento desenvolvidas ao menos do século XIX aos dias de hoje.

O livro está organizado em três partes que trazem além de relatos etnográficos, análises contemporâneas sobre o campo, tornando-se meio através do qual o leitor acessa trabalhos atuais de pesquisadores de referência no Brasil. Os organizadores trabalharam para oferecer ampla gama de discussões, selecionando alguns dos debates que permeiam o mundo dos museus e coleções. Como num exercício de curadoria, os artigos foram arranjados de modo a contemplar aspectos centrais nos processos de atualização de museus e coleções frente aos novos desafios que os acompanham: das reivindicações de 
discursos e patrimônios a partir do cenário pós-colonial, à presença e participação dos povos tradicionalmente representados na organização, classificação e composição de exposições sob sua perspectiva. A ênfase no processo de coleta de objetos e referências, nas implicações identitárias intrínsecas à produção material local e os diálogos que daí partem desafiam o trabalho do antropólogo a se renovar e se reestruturar sob outras condições, exigidas pela entrada de novos atores sociais de que trata o livro.

A primeira parte dedica-se aos "Museus e a (des)construção de identidades culturais", tratando dos sentidos identitários e de memória coletiva implicados na composição de coleções e exposições. Iniciando com o artigo de João Pacheco de Oliveira e Rita de Cássia Melo Santos, o livro abre o debate recuperando o histórico de museus e exposições coloniais do século XIX e a exibição de um "outro exótico". Os autores questionam o que chamam de ilusão museal, quando para falar sobre pessoas e coletividades vivas, os museus utilizam-se de objetos e imagens do passado, produzindo entendimentos dúbios que impactarão em políticas e ideologias contemporâneas. Repensando a partir da exposição Os Primeiros Brasileiros, os autores exploram o que significa descolonizar os acervos de museus num cenário em que a estética torna-se aliada das transformações recentes nas instituições.

Fernando Barona Tovar traz a perspectiva colombiana sobre o surgimento e a permanência dos museus de antropologia, expondo as fases iniciais do desenvolvimento da disciplina no país, das influências estrangeiras à virada pós-moderna dos anos 1990. O trabalho do autor dialoga com outros ao longo do livro ao ressaltar a escassez do tema das comunidades negras nas pesquisas antropológicas na Colômbia, em proveito do que foi considerado o "outro primitivo" e isolado. Os estudos sobre as comunidades indígenas, originários da postura "civilizatória" e dos discursos nacionalistas que acompanharam a constituição de seu Museo Nacional, recentemente passaram a enfrentar as lutas dos movimentos indigenistas por marcar sua especificidades cultural e não dissolverem-se no plano modernizador da sociedade mais ampla.

A trajetória de Luís da Câmara Cascudo (1898-1986), seu impulso colecionista e inconformidades com a prática acadêmica integram o artigo de Julie Antoinette Cavignac, que apresenta ao leitor a relação deste destacado personagem potiguar junto a outra figura ilustre do folclorismo brasileiro, Mário de Andrade. As correspondências trocadas pelos pesquisadores são analisadas pela autora, buscando a influência mútua que exerceram na perspectiva de construção do projeto modernista por um lado, e na descoberta de sertões e litorais inexplorados por outro. Traz ainda documentos e narrativas sobre suas experimentações etnográficas, que produziram registros fotográficos, gravações sonoras, filmagens e coleta de objetos nas viagens pelo Nordeste no final dos anos 1920.

Apresentando o Projeto Memória, Cultura, Transformaçóes Sociais e Desenvolvimento: panorama museal do Estado do Rio de Janeiro, Regina Abreu e Renata Almeida de Oliveira exploram a "etnografia dos percursos", metodologia utilizada neste trabalho de mapeamento de experiências relacionadas às memórias e museus na região. Baseadas na perspectiva dos viajantes que descobrem um novo lugar, as autoras utilizam-se de filmagens, fotografias, cartografias e diário de campo para identificar instituições, projetos e personagens do Estado, com o objetivo de constituir um banco de dados acessível capaz de subsidiar novas pesquisas. Trazem ainda a análise de casos que tornaram-se emblemáticos do con- 
texto de crescimento das requisições de valorização de memórias locais e identidades, como as histórias descobertas sobre o Museu da Maré, inaugurado em 2006.

Encerrando a primeira parte do livro, Nei Clara de Lima narra a partir dos anos 1970 o trabalho do Museu Antropológico da Universidade Federal de Goiás pela coleta de artefatos arqueológicos e etnográficos indígenas e de populações interioranas. Contrasta duas exposições realizadas, Museu expressão da vida e Lavras e louvores, como casos para pensar a transformação de abordagens museográficas ao longo das últimas décadas, passando da busca pelo "autêntico" e "tradicional" ao questionamento da dualidade sertão/civilização fortemente explorada no Centro-Oeste do Brasil. Neste percurso, o "sertão" torna-se categoria de narrativa cultural. A autora aborda a construção de seus sentidos ao longo do tempo e como confere identidade aos que habitaram e habitam a região.

A segunda parte do livro, "Museus e o diálogo intercultural”, trabalha a dinâmica indígena em contato com instituições museais e colecionistas. Colaboração de saberes torna-se ponto central nas experiências de curadoria compartilhada entre indígenas e não indígenas no que tange aos artefatos etnográficos coletados desde os tempos coloniais ou recentemente produzidos para fins museológicos. Nesta linha, Marília Cury descreve o processo de trabalho do Museu de Arqueologia e Etnologia da Universidade de São Paulo, em parceria com a Associação Cultural de Apoio ao Museu Casa de Portinari e o Museu Histórico e Pedagógico Índia Vanuíre em recompor histórias de subordinação e colonialismo vivenciadas pelos indígenas da região de Tupã/SP. Diante da constante referência ao fundador da cidade e do museu nas exposições anteriores, a autora contrasta os paradigmas tradicional e emergente ao discutir os novos usos do museu por seus visitantes quando a exposição é proposta, concebida e montada com a colaboração dos próprios indígenas.

Olhar para os objetos guardados pelos museus sob a ótica da cosmologia indígena é a que se dedica Manuel Ferreira Lima Filho em seu artigo sobre o significado das coisas Karajá. O autor mapeia referências nacionais e internacionais a respeito da cultura material ameríndia e suas perspectivas contemporâneas de análise e enquadramento. Tomando coleções como categorias de pensamento, a interação de grupos indígenas com os objetos coletados e a produção intelectual de destacados colecionadores, o autor apresenta e analisa as coleçôes Karajá do Museu Nacional do Rio de Janeiro, composta por 359 objetos reunidos por William Lipkind.

Renato Athias comenta a especificidade dos objetos produzidos em contexto rituais pelos indígenas. Recuperando suas histórias a respeito dos objetos do Alto Rio Negro espalhados por museus no Brasil e no mundo, o autor discute as idiossincrasias do registro da "cultura material e imaterial" indígena, num cenário em que pouco incorpora as narrativas locais sobre suas práticas. $\mathrm{O}$ autor traz o caso da recente patrimonialização da Cachoeira de Iauareté como lugar dos índios Tariana. Terra de muitos outros povos indígenas de língua Tukano, torna-se emblemática para pensar a serviço de quê estariam estes processos de registro e proteção cultural, dada a condição transformadora mesma da cultura.

A terceira parte contempla especificamente registros sonoros, contribuindo com análises apuradas sobre uma forma de colecionamento distinta dos objetos exibidos em exposiçóes. Da gravação de canções, tornadas referência pelo fato de terem sido alvo de registro e arquivamento, às apropriações 
decorrentes destes processos, os trabalhos apresentados revelam um campo pouco explorado de análise sobre as condições e as implicações dos métodos e suportes técnicos empregados.

Dois trabalhos compõem este grupo. No primeiro, Edmundo Pereira expõe o processo de gravação do CD Ile Omolu Oxum, cantigas e toques para os Orixás, para questionar as imaginações museais coloniais, como as classificações atribuídas à música ocidental quando posta em relação ao que as demais sociedades produzem. O autor debate ainda as implicações da objetificação de poemas, canções e melodias, discutindo quando tornam-se referentes e passam a funcionar como suportes de memórias tanto para pesquisadores quanto para os produtores locais e seus descendentes. Por outro lado, analisa que os registros permitem acompanhar a longo prazo perspectivas do presente, como a influência do público sobre o performer, os erros e continuidades, e as condições próprias e específicas da situação de execução do ato, seja em gravação de estúdio ou num ritual.

O trabalho de Wagner Diniz Chaves encerra a terceira parte através da trajetória do folclorista Theo Brandão, reunindo registros sonoros tradicionais do Estado de Alagoas em meados do século $\mathrm{XX}$. Em contato com este acervo depositado no museu que o homenageia, o autor recupera o percurso do colecionista que, por conta própria, registrou in loco e também em sua própria casa canções do bumba-meu-boi ao maracatu. Os registros passaram pelo Instituto Nacional do Folclore sendo então reclassificados como "coleção", e hoje compõem o museu. Longe de integrar um conjunto de documentos de um passado condenado ao esquecimento, os materiais passam a integrar novos circuitos de músicos, pesquisadores e interessados.

Por fim, o posfácio de Sally Price agrega à coletânea o contexto internacional da utilização de objetos ditos "etnográficos" em distintas abordagens. A autora discute o silenciamento e a higienização de narrativas em exposições, citando casos em que verifica-se a criação de ambientes homogêneos e não contraditório como forma de garantir o entusiasmo do público visitante. Segundo a autora, este processo acontece às custas do apagamento tanto da história quanto do significado cultural do que exibem. Price comenta observações feitas por ela em museus na Europa e nas Américas, destacando o constrangimento em expor o colonialismo, o tráfico de escravos e a aquisição ilegal e irregular de objetos como constituinte das coleções que exibem.

Talvez um dos pontos chave deste terceiro volume seja enxergarmos um panorama geograficamente amplo das abordagens, dos museus localizados no sudeste do país, irradiando para o Norte, Nordeste e interior dos Estados. Contempla não apenas instituições, mas especialmente coleções, descrevendo o modus operandi da coleta por parte de folcloristas e antropólogos, bem como o fluxo inerente aos objetos em seus contextos de origem.

O livro corresponde essencialmente ao cenário brasileiro de museus e instituições desafiados pelos novos paradigmas de atualização de acervos e exposições. Neste horizonte, considera os povos tradicionalmente representados como parte do grupo responsável por pensar a interpretação que produzem nas vitrines e catalogação de coleções. Torna-se, portanto, também parte de uma coleção que documenta e pontua os debates atuais entorno dos objetos coletados em tempos variados, e que demandam novas posições mais interativas e igualitárias. 
Renata Montechiare, doutora pelo Programa de Pós-Graduação em Sociologia e Antropologia, IFCS, UFRJ.

RECEBIDO: 03/04/2017

APROVADO: 04/10/2017 
198 CAMPOS V.17 N.2 jul.dez.2016 